\title{
Chemistry of sprite discharges through ion-neutral reactions
}

\author{
Y. Hiraki ${ }^{1}$, Y. Kasai ${ }^{2}$, and H. Fukunishi ${ }^{3}$ \\ ${ }^{1}$ Solar-Terrestrial Environment Lab, Nagoya University, Nagoya, Japan \\ ${ }^{2}$ National Institute of Information and Communications Technology (NICT), Koganei, Tokyo, Japan \\ ${ }^{3}$ Department of Geophysics, Tohoku University, Sendai, Miyagi, Japan
}

Received: 12 October 2007 - Published in Atmos. Chem. Phys. Discuss.: 8 February 2008

Revised: 19 May 2008 - Accepted: 19 May 2008 - Published: 23 July 2008

\begin{abstract}
We estimate the concentration changes, caused by streamer discharge in sprites, of ozone and related minor species as odd nitrogen $\left(\mathrm{NO}_{\mathrm{x}}\right)$ and hydrogen $\left(\mathrm{HO}_{\mathrm{x}}\right)$ families in the upper stratosphere and mesosphere. The streamer has an intense electric field and high electron density at its head, where a large number of chemically-radical ions and atoms are produced through electron impact on neutral molecules. After its propagation, densities of minor species can be perturbed through ion-neutral chemical reactions initiated by the relaxation of these radical products. We evaluate the production rates of ions and atoms using an electron kinetics model and by assuming that the electric field and electron density are in the head region. We calculate the density variations mainly for $\mathrm{NO}_{\mathrm{x}}, \mathrm{O}_{\mathrm{x}}$, and $\mathrm{HO}_{\mathrm{x}}$ species using a one-dimensional model of the neutral and ion composition of the middle atmosphere, including the effect of the sprite streamer. Results at the nighttime condition show that the densities of $\mathrm{NO}, \mathrm{O}_{3}, \mathrm{H}$, and $\mathrm{OH}$ increase suddenly through reactions triggered by the first atomic nitrogen and oxygen product, and electrons just after streamer initiation. It is shown that $\mathrm{NO}$ and $\mathrm{NO}_{2}$ still remain for $1 \mathrm{~h}$ by a certain order of increase with their source-sink balance, predominantly around $60 \mathrm{~km}$; for other species, increases in $\mathrm{O}_{3}, \mathrm{OH}$, $\mathrm{HO}_{2}$, and $\mathrm{H}_{2} \mathrm{O}_{2}$ still remain in the range of $40-70 \mathrm{~km}$. From this affirmative result of long-time behavior previously not presented, we emphasize that sprites would have the power to impact local chemistry at night. We also discuss the consistency with previous theoretical and observational studies, along with future suggestions.
\end{abstract}

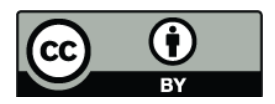

Correspondence to: Y. Hiraki

(hiraki@stelab.nagoya-u.ac.jp)

\section{Introduction}

Sprites are lightning-induced secondary discharges with both lateral and vertical scales of tens of kilometers appearing at the middle atmosphere all over the world. Tens or more of events can occur during one night, especially in Africa, as clearly identified by FORMOSAT-2 satellite observations (Pasko, 2007, and references therein). The overall time scale of sprites are in the range of 1-100 ms (São Sabbas et al., 2003; Moudry et al., 2003). From telescopic imaging observations it is found that the structure of the emission dominates in a cluster of thin channels with a scale of $1-10 \mathrm{~m}$ called streamers (Gerken and Inan, 2002; Liu and Pasko, 2004). From high temporally resolved observations it is found that the sprite streamers initiate around $60-70 \mathrm{~km}$ altitude and develop up to $\approx 90 \mathrm{~km}$ and down to $40 \mathrm{~km}$ with a velocity of $10^{7}-10^{8} \mathrm{~cm} / \mathrm{s}$ (Moudry et al., 2003; McHarg et al., 2002). Results of spectral observations demonstrated that the emission is due to excitation of $\mathrm{N}_{2}(\mathrm{~B}, \mathrm{C})$ states and ionization excitation of $\mathrm{N}_{2}^{+}(\mathrm{A}, \mathrm{B})$ through electron acceleration (e.g. Morrill et al., 2002). A streamer is a highly conducting plasma channel; as the tip propagates with a high electric field and a high electron density, a large amount of ions and electrons is produced and released over its path, through collisions with neutral gases (mainly $\mathrm{N}_{2}$ and $\mathrm{O}_{2}$ ) of electrons accelerated by the field. Radical ions and atoms produced are considered to induce various chemical reactions. Leading to the removal of harmful components in atmospheric pressure, the streamer corona is expected to be one of the useful tools for flue gas cleaning; technological application is promoted since it causes no significant gas heating (Kulikovsky, 1997).

It has been suggested that sprites can have an impact on upper stratospheric and mesospheric ozone chemistry, which is triggered by a cluster of streamers having the above characteristics (Stenbaek-Nielsen et al., 2000; Sentman and São

Published by Copernicus Publications on behalf of the European Geosciences Union. 
Sabbas, 2002; Hiraki et al., 2004; Enell et al., 2005, 2008; Arnone et al., 2008). Here, we make a rough estimation as to how large an impact is actually expected from the generation of ions and atoms (e.g. $\mathrm{N}_{2}^{+}, \mathrm{N}$, and $\mathrm{O}\left({ }^{1} \mathrm{D}\right)$ ) through electronmolecule collision in the high electric field. On the basis of laboratory and numerical studies the electron density at the streamer tip is typically $n_{\mathrm{es}} \simeq 10^{14} \mathrm{~cm}^{-3}$, approximately uniform (e.g. Kulikovsky, 1997 and references therein). The amount of ions and atoms produced is considered to be comparable to $n_{\text {es }}$ or larger, and is estimated to be $\approx 10^{9} \mathrm{~cm}^{-3}$ at the altitudes of $40-50 \mathrm{~km}$ by assuming a scaling relation of $n_{\mathrm{es}} \sim N^{2}$, with $N$ being atmospheric gas density (Pasko et al., 1998). This corresponds to $\approx 1 \%$ of ozone density at this altitude range (Brasseur, 1999). Meanwhile, the impact on nitric oxide NO is expected to be relatively large because its ambient density is only $10^{6} \mathrm{~cm}^{-3}$ or less at night. Impacts are also expected for other species as $\mathrm{NO}_{2}$ with density of $10^{8}-10^{9} \mathrm{~cm}^{-3}$ and $\mathrm{HO}_{\mathrm{x}}$ with densities of $10^{4}-10^{7} \mathrm{~cm}^{-3}$.

It is, however, not so easy to understand whether the densities of ozone, $\mathrm{NO}_{\mathrm{x}}\left(\mathrm{NO}\right.$ and $\left.\mathrm{NO}_{2}\right)$, and $\mathrm{HO}_{\mathrm{x}}(\mathrm{H}, \mathrm{OH}$, $\mathrm{HO}_{2}$, and $\mathrm{H}_{2} \mathrm{O}_{2}$ ) finally increase or decrease. This is because the upper-stratospheric chemistry, controlled mainly by $\mathrm{NO}_{\mathrm{x}}, \mathrm{HO}_{\mathrm{x}}$, and $\mathrm{O}_{\mathrm{x}}\left(\mathrm{O}_{3}\right.$ and $\left.\mathrm{O}\right)$ is a nonlinear system. $\mathrm{NO}_{\mathrm{x}}$ and $\mathrm{HO}_{\mathrm{x}}$ species, which destroy ozone through catalytic reactions (Brasseur, 1999), can increase by one reaction and decrease by other reactions related to sprite products, such as nitrogen atom $\mathrm{N}$; for $\mathrm{NO}$, an expected source reaction is $\mathrm{N}+\mathrm{O}_{2} \rightarrow \mathrm{NO}+\mathrm{O}$ and a sink one is $\mathrm{N}+\mathrm{NO} \rightarrow \mathrm{N}_{2}+\mathrm{O}$. For $\mathrm{OH}$, the source can be $\mathrm{H}_{2} \mathrm{O}+\mathrm{O}\left({ }^{1} \mathrm{D}\right) \rightarrow 2 \mathrm{OH}$, which is a main ambient reaction in the $D$ region, while the sink is $\mathrm{OH}+\mathrm{O} \rightarrow \mathrm{H}+\mathrm{O}_{2}$.

In this study we perform a numerical simulation with a one-dimensional ion-neutral chemical model including the effect of the modeled sprite streamer. The purposes are to find the way to relax minor species after the event, along with its altitude dependence, and to make clear the above obscure point in the nighttime condition. The reason we focus on the nighttime impact is that the NO density is lower at night, as shown above, making easy to detect a perturbation by a streamer. However, it is difficult to be detected in the daytime case because the ambient density of $\mathrm{NO}$, as well as that of $\mathrm{NO}_{2}$, is comparable through photolysis of $\mathrm{NO}_{2}$ with the perturbation estimated above.

It is worth mentioning the importance of the impact on $\mathrm{NO}_{\mathrm{x}}$ in the upper-stratosphere and mesosphere. The main ozone destroyer is generally considered to be the $\mathrm{HO}_{\mathrm{x}}$ species in these regions (Brasseur, 1999). However, it is possible that $\mathrm{NO}_{\mathrm{x}}$ supersedes $\mathrm{HO}_{\mathrm{x}}$ as the position of ozonereactor if its density increases considerably through for example oxidation of $\mathrm{N}$ shown above after the occurrence of sprites. Only a few evidences implying this enhancement have been reported because of limited spatial and temporal resolutions and the sensitivity of optical instruments. Arnone et al. (2008) reported the signatures of correlation between lightning activity and density anomalies of $\mathrm{NO}_{2}$ around $50 \mathrm{~km}$, using the data set of MIPAS on board the ESA Environmental Satellite (ENVISAT). Their results show that nighttime enhancements of $\mathrm{NO}_{2}$ around $50 \mathrm{~km}$ in the active area are up to $10 \%$ of the background levels. We compare it with our results along with the suggestion for future cooperative studies between observation and theory for an understanding of the strongly enhanced and eccentric local chemistry above the thundercloud in Sect. 4.

\section{Model description}

Using an ion-neutral chemical model we calculate temporal density variations for various atmospheric species in the relaxing phase after the occurrence of a sprite streamer at each altitude. The reaction rate coefficients between streamer electrons and major species, $\mathrm{N}_{2}$ and $\mathrm{O}_{2}$, can be expressed as a function of local electric field. For simplicity we do not solve the streamer dynamics directly, but rather we assume its tip field magnitude and its crossing time at a certain altitude and evaluate the production rates of the radical particles. We consider that a reasonable evaluation of the impact as our approach will bring realistic results of a chemical model calculation, even though the model generally has an uncertainty depending on schemes and rate coefficients.

\subsection{Sprite model}

\subsubsection{Parameterization of streamer}

We suppose that the radical particles are produced predominantly at the streamer tip. We assume roughly that the tip has an impulsive electric field with a width of $r_{\mathrm{s}}$ and a uniform amplitude of $E_{\mathrm{S}}$, and the electron density at the region being uniform as $n_{\mathrm{es}}$. Here, we assume $r_{\mathrm{s}}$ is in the same order as the streamer radius (Raizer, 1991). We can consider that the lightning-induced electric field above the thundercloud is directed almost vertically, and that the streamer propagates along its direction with the constant velocity of $v_{\mathrm{s}}$; note that this is really an assumption, as it tends to curve and converge to the thundercloud charge center at the lower parts of $40-50 \mathrm{~km}$ (Neubert et al., 2005). Therefore, the time scale of electron acceleration, i.e. particle production, at a certain altitude is given as $t_{\mathrm{s}}=r_{\mathrm{s}} / v_{\mathrm{s}}$. Numerical simulations showed that $E_{\mathrm{s}}, n_{\mathrm{es}}, r_{\mathrm{s}}$, and $v_{\mathrm{s}}$, characterizing the streamer, depend on boundary conditions (shapes of electrodes and applied field magnitude) and the polarity. For simplicity and maximum estimation, we set these values as $E_{\mathrm{s}}=150 \mathrm{kV} / \mathrm{cm}, n_{\mathrm{es}}=10^{14} \mathrm{~cm}^{-3}, r_{\mathrm{s}}=10^{-1} \mathrm{~cm}$, and $v_{\mathrm{s}}=10^{7} \mathrm{~cm} / \mathrm{s}$ within the realistic range based on the numerical study in Kulikovsky (1997). These parameters are assumed to be scaled as $\sim N, \sim N^{2}, \sim N^{-1}$, and $\sim 1$, respectively, using atmospheric gas density $N$; for example, $r_{\mathrm{s}}=10^{-1}\left(N_{0} / N\right) \mathrm{cm}$, with $N_{0}$ being the ground value, and at $70 \mathrm{~km} r_{\mathrm{s}} \simeq 10 \mathrm{~m}, t_{\mathrm{s}} \simeq 100 \mu \mathrm{s}$. We neglect here the effect 
of the photoionization process excited through electron collisions, although it is an important process for local streamer dynamics and makes these parameters slightly shifted from the above $N$-scaling values (Liu and Pasko, 2004).

\subsubsection{Radical products}

We assume that the accelerated electrons at the streamer tip collide only with $\mathrm{N}_{2}$ and $\mathrm{O}_{2}$. The collision rate coefficients $k$ are given as a function of reduced electric field $E / N$ through the steady-state energy distribution function of electrons along with collision cross sections. On the basis of a numerical study with a Monte Carlo technique (Hiraki et al., 2004), the relaxation time of the energy distribution is much smaller than the streamer lifetime $t_{\mathrm{s}}$ at the altitude of our interest, and the major composition of the atmosphere hardly changes in the time scale of $t_{\mathrm{s}}$. In what follows, the production rate of a particle $\mathrm{j}$ is given constantly as $P_{\mathrm{j}}=k_{\mathrm{j}}\left(E_{\mathrm{s}} / N\right) N n_{\mathrm{es}}$ all through the streamer propagation. We obtain the electron energy distribution function with a Monte Carlo technique. Here we take the cross sections of e- $\mathrm{N}_{2}$, $\mathrm{O}_{2}$ collisions from an updated compilation by Itikawa (2006, 1994), respectively. We consider, as radical particle $\mathrm{j}$, atoms of $\mathrm{O}\left({ }^{1} \mathrm{D}\right), \mathrm{O}\left({ }^{3} \mathrm{P}\right), \mathrm{N}\left({ }^{4} \mathrm{~S}\right)$, and $\mathrm{N}\left({ }^{2} \mathrm{D}\right)$, and adopt the cross section data in Cosby (1993a, b) and Itikawa (1994); the excited species of $\mathrm{O}_{2}\left(\mathrm{a}^{1} \Delta_{\mathrm{g}}\right)$ and $\mathrm{N}_{2}\left(\mathrm{~A}^{3} \Sigma_{\mathrm{u}}^{+}\right)$and ionic species of $\mathrm{O}^{+}, \mathrm{O}_{2}^{+}, \mathrm{O}^{-}, \mathrm{N}^{+}$, and $\mathrm{N}_{2}^{+}$are considered by including the cascade effects from $\mathrm{O}_{2}(\mathrm{~b}), \mathrm{N}_{2}(\mathrm{~B}, \mathrm{C}), \mathrm{O}_{2}^{+}(\mathrm{a}, \mathrm{b}, \mathrm{A})$, and $\mathrm{N}_{2}^{+}$(A, B). Cross sections for all these particles are taken from Itikawa $(1994,2006)$. We disregard other possible source processes. We obtain the most reliable set of production rates, especially for atomic nitrogen and oxygen of critical importance in the following calculation, by recalculating electron energy distribution with updated cross sections of $\mathrm{N}_{2}$ by Hiraki and Fukunishi (2006).

\subsection{Chemical model}

We represent the chemical impact of the sprite streamer with two parameters, $P_{\mathrm{j}}$ and $t_{\mathrm{s}}$, both of which are only functions of altitude through $N$. We estimate composition changes at altitudes of 40-90 km, using a one-dimensional chemical model after the occurrence of the modeled streamers at each altitude. We adopt basically the chemical model of neutral atmosphere by Iwagami et al. (1998). This model treats 40 neutral species including $\mathrm{O}_{2}(\mathrm{a}), \mathrm{O}\left({ }^{1} \mathrm{D}\right), \mathrm{O}\left({ }^{3} \mathrm{P}\right)$, and $\mathrm{N}\left({ }^{4} \mathrm{~S}\right)$ shown above, with about 100 reactions, and covers the altitude range of $0-90 \mathrm{~km}$; reaction coefficients are taken from DeMore et al. (1994). We include thermal electrons and 34 ionic species, such as $\mathrm{O}_{\mathrm{i}}^{ \pm}, \mathrm{N}_{\mathrm{i}}^{+}$, and $\mathrm{NO}_{\mathrm{i}}^{ \pm}(\mathrm{i} \leq 4)$, with about 400 ion-neutral reactions into the above model on the basis of reaction data by Borisov et al. (1993), Tochikubo and Arai (2003), and Matzing (1991).
In order to obtain a reference diurnal density variation used for initial values we first make a temporal integration (hundreds of days) of rate equations $\mathrm{d}_{t} n=P-L n$ of all ions and neutrals at altitudes of $0-90 \mathrm{~km}$ with the day of the year and with moderate solar activity being fixed on the basis of Iwagami et al. (1998). Here we include the vertical eddy and molecular diffusions for neutral species. Adding the production terms $P_{\mathrm{j}}$ of radical particles and taking the reference density data at an arbitrary local time $t_{0}$, we solve the rate equations for all species separately without the assumption of families until the time $t=t_{0}+t_{\text {relax }}$ by an implicit method. It is noted that the sprite impacts $P_{\mathrm{j}}$ are non-zero at each altitude at $t \leq t_{\mathrm{s}}$. Here we disregard the vertical diffusion term, in order to focus the streamer effect on local chemistry at each altitude. This assumption is still valid because the initiations of actual streamers at different altitudes do not coincide at $t_{0}$ with millisecond orders of delay and the effects should be treated separately. The electron temperature used for calculation of reaction coefficients is assumed to be $10 \mathrm{eV}$ at the period of $t_{0}<t<t_{0}+t_{\mathrm{s}}$, after which it equals the neutral temperature, while the ion temperature is not perturbed at all. We assume the neutral temperature to be unchanged from the ambient values because Joule heating by sprite discharge may be negligibly small. If one tries to estimate roughly the secondary sprite impact occurring with a certain delay (e.g. $\approx 100 \mathrm{~s}$ ), it is easy to multiply the values of our calculation, e.g. 2 orders of magnitude $\times 2$, as discussed in the Discussion section. We can suppose that the primary effect seems to be advected far away $(\approx 1 \mathrm{~km})$ by the horizontal wind, $\approx 10 \mathrm{~m} / \mathrm{s}$. It is, however, noted that the local overlapping and mixing effects make the problem complicated, since the advection scale is apparently less than the overall scale (tens of kilometer) of sprites. Hereafter, we redefine $t=t_{0}$ as $t=0$.

\section{Numerical simulation and results}

We focus on the chemical impact of sprites in the nighttime stratosphere and mesosphere, where most of events are observed. In this paper we estimate only the impact of the streamer head where a large amount of radical particles are produced in a strong electric field. We show first in Fig. 1 the production rate coefficients of $\mathrm{N}\left({ }^{4} \mathrm{~S}\right), \mathrm{N}\left({ }^{2} \mathrm{D}\right), \mathrm{O}\left({ }^{3} \mathrm{P}\right)$, and $\mathrm{O}\left({ }^{1} \mathrm{D}\right)$ atoms through electron impact dissociations of molecular nitrogen and oxygen calculated with a Monte Carlo method. Streamer electric field, $150 \mathrm{kV} / \mathrm{cm}$ at ground level, corresponds to a reduced value of $E / N=600 \mathrm{Td}$; in this field the average electron energy $\approx 12 \mathrm{eV}$ exceeds the dissociation limit. The coefficients of the above atomic production and ionization show the largest values at this field among inelastic processes, such as excitation to a metastable state. It is also found that these values are much larger than a typical ion-molecular reaction coefficient $\left(\approx 10^{-10} \mathrm{~cm}^{-3} \mathrm{~s}^{-1}\right)$ in the atmosphere. It is 


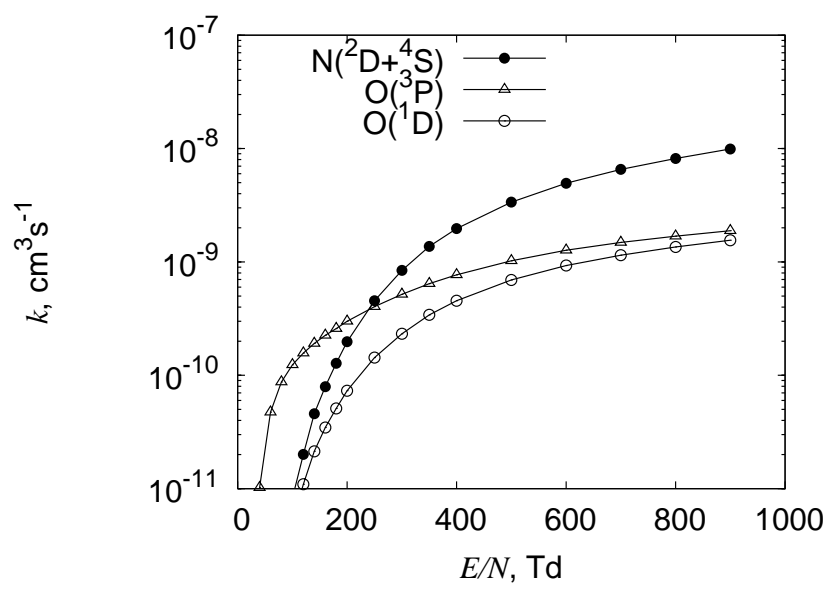

Fig. 1. Rate coefficients $k$ of electron impact dissociative excitations of $\mathrm{N}_{2}$ and $\mathrm{O}_{2}$ as a function of reduced electric field $E / N$; we use cross sections for the fragments of $\mathrm{N}\left({ }^{2} \mathrm{D}\right)+\mathrm{N}\left({ }^{4} \mathrm{~S}\right), \mathrm{O}\left({ }^{3} \mathrm{P}\right)+\mathrm{O}\left({ }^{3} \mathrm{P}\right)$ (the lower threshold), and $\mathrm{O}\left({ }^{3} \mathrm{P}\right)+\mathrm{O}\left({ }^{1} \mathrm{D}\right)$, and multiply the mixing ratio as $\mathrm{N}_{2}: \mathrm{O}_{2}=0.8: 0.2$ for illustration.

clear from a simple estimation that the amount of the $\mathrm{N}$ atom produced, written as $k_{\mathrm{diss}} N n_{\mathrm{es}} t_{\mathrm{s}}$, overwhelms the ambient one, which is negligibly small below the $70 \mathrm{~km}$ altitude: $k_{\text {diss }} \approx 5 \times 10^{-9} \mathrm{~cm}^{3} \mathrm{~s}^{-1}, n_{\mathrm{es}}=10^{14}\left(N / N_{0}\right)^{2} \mathrm{~cm}^{-3}$, and $t_{\mathrm{s}}=10^{-8}\left(N_{0} / N\right) \mathrm{s}$. Furthermore, it is in the same order or exceeds the nighttime NO density at the altitude range of 40 $70 \mathrm{~km}$.

We solve rate equations to calculate the density changes for various species when a single streamer effect as source term $P=k_{\mathrm{j}} N n_{\mathrm{es}}$ is given at the altitudes of $40-90 \mathrm{~km}$. Here we assume the fixed conditions, such as temperature being at mid-latitude $\left(\approx 36^{\circ} \mathrm{N}\right)$ equinox (Iwagami et al., 1998). Firstly, we show in Fig. 2 the density distributions of $\mathrm{NO}_{\mathrm{x}}$ ( $\mathrm{NO}$ and $\mathrm{NO}_{2}$ ) species, one second and one hour after the initiation of a single streamer. Note for initial values that the sharp drop in NO typically seen around $50 \mathrm{~km}$ (Enell et al., 2008) shifts higher to $70 \mathrm{~km}$ in our case. This is due to the weakness of its flux from the thermosphere assigned in our model. We find that the NO density increases strongly at $t=1 \mathrm{~s}$, whereas $\mathrm{NO}_{2}$ does not change so much except below $55 \mathrm{~km}$, since $\mathrm{NO}_{2}$ is abundant as $\mathrm{NO}_{\mathrm{x}}$ below $70 \mathrm{~km}$ at night, and above the altitude, the sprite impact itself is too small. We also find that a decrease in $\mathrm{NO}_{2}$ below $55 \mathrm{~km}$ is due to negative-ion reactions related to strongly enhanced $\mathrm{N}$, $\mathrm{O}$, and NO. The key reactions of the increase in NO density (up to $10^{11} \mathrm{~cm}^{-3}$ at $t \leq 1 \mathrm{~s}$ ) are electron impact dissociation of $\mathrm{N}_{2}$ and oxidation of $\mathrm{N}$ atom as a series below,

$$
\begin{aligned}
& \mathrm{N}_{2}+\mathrm{e} \rightarrow \mathrm{N}\left({ }^{4} \mathrm{~S}\right)+\mathrm{N}\left({ }^{2} \mathrm{D}\right)+\mathrm{e} \\
& \mathrm{N}+\mathrm{O}_{2} \rightarrow \mathrm{NO}+\mathrm{O} .
\end{aligned}
$$

This response is consistent with the maximum production of $\mathrm{N}, P_{\text {diss }} t_{\mathrm{s}} \approx 1.2 \times 10^{12} \mathrm{~cm}^{-3}$ at $40 \mathrm{~km}$. The saturation around $40 \mathrm{~km}$ is caused by the $\mathrm{NO}_{\mathrm{x}}$ reduction process as
$\mathrm{N}+\mathrm{NO} \rightarrow \mathrm{N}_{2}+\mathrm{O}$. Note that the $\mathrm{N}$ atoms in the second equation are mostly in the state of ${ }^{4} \mathrm{~S}$, while the excited state ${ }^{2} \mathrm{D}$ is already lost at this moment. It is, however, confirmed that the effect on the $\mathrm{NO}_{\mathrm{x}}$ species continues over $1 \mathrm{~s}$, in spite of the assumed lifetime of sprites less than $1 \mathrm{~ms}$ (maximum at $90 \mathrm{~km}$ ). The increasing rate of NO is up to 5-9 orders of magnitude at the altitude range of $40-70 \mathrm{~km}$. We would investigate the response at $1 \mathrm{~h}$ after the event, even if it is an order-estimation, in order to discuss the effect on atmospheric chemistry. The noticeable enhancements sustain around $60 \mathrm{~km}$ for $\mathrm{NO}$ and $40-60 \mathrm{~km}$ for $\mathrm{NO}_{2}$ (Fig. 2). In particular, we show in Fig. 3 the time variation in $\mathrm{NO}$ and $\mathrm{NO}_{2}$ densities at $60 \mathrm{~km}$. We find from this figure and by checking the dominant reactions that $\mathrm{NO}$ sustains its amount through the relaxation of ions and atoms as $\mathrm{N}$ at the initial phase $(t \leq 100 \mathrm{~s})$; after that, almost all convert to $\mathrm{NO}_{2}$ through the following processes:

$$
\begin{aligned}
& \mathrm{NO}+\mathrm{O}_{3} \rightarrow \mathrm{NO}_{2}+\mathrm{O}_{2} \\
& \mathrm{NO}+\mathrm{O}+\mathrm{M} \rightarrow \mathrm{NO}_{2}+\mathrm{M} \\
& \mathrm{NO}+\mathrm{HO}_{2} \rightarrow \mathrm{NO}_{2}+\mathrm{OH} .
\end{aligned}
$$

This is because the response of $\mathrm{NO}_{2}$ is in anti-phase to NO, resulting in the remarkable increase at $t=1 \mathrm{~h}$. It is confirmed that the dominant loss reactions of $\mathrm{NO}_{2}$ are $\mathrm{NO}_{2}+\mathrm{O} \rightarrow \mathrm{NO}+\mathrm{O}_{2}$ and $\mathrm{NO}_{2}+\mathrm{H} \rightarrow \mathrm{NO}+\mathrm{OH}$. Thus, the loss rate of $\mathrm{NO}$ becomes relatively small around $60 \mathrm{~km}$ due to the source-sink balance in $\mathrm{NO}_{\mathrm{x}}$ by the above five reactions. Contrary to the linear response to sprite impact at $t=1 \mathrm{~s}$, these particles are strongly coupled each other, along with weak couplings with $\mathrm{O}_{\mathrm{x}}$ and $\mathrm{HO}_{\mathrm{x}}$ in this time scale. It is mentioned that $\mathrm{NO}_{2}$ is the final sink of $\mathrm{NO}_{\mathrm{x}}$ to the sprite impact; its density amounts to $\approx 6 \times 10^{9} \mathrm{~cm}^{-3}$ at $40 \mathrm{~km}$. The increasing rates at $t=1 \mathrm{~h}$ are summarized as, for NO, up to 6 orders of magnitude with its maximum around $60 \mathrm{~km}$, while for $\mathrm{NO}_{2}, 1$ order of magnitude at the range of 40-60 km. We emphasize from this result that the impact can be sustained for a few hours. In addition to the above key reactions, ineffectiveness of the reaction $\mathrm{N}+\mathrm{NO} \rightarrow \mathrm{N}_{2}+\mathrm{O}$ has a critical role because the impact will diminish perfectly if this reaction rate is so large. It is slightly seen as a saturation of the increasing rate of $\mathrm{NO}_{2}$ at $t=1 \mathrm{~h}$ at $40 \mathrm{~km}$. However, we can interpret that the conversion of $\mathrm{N} \rightarrow \mathrm{NO} \rightarrow \mathrm{NO}_{2}$ is smoothly proceeded within $1 \mathrm{~h}$ with a negligible contribution of this reaction, since the production rate of $\mathrm{N}$ is smaller at higher altitude and its loss time scale is smaller at lower altitude $(\approx 1-10 \mathrm{~s})$. We also confirmed that the contribution of ion-molecular reactions to the $\mathrm{NO}_{\mathrm{x}}$ chemistry is restricted within $t=1-10 \mathrm{~s}$ and do not work at all at $t=1 \mathrm{~h}$.

Next, we show density distributions of $\mathrm{O}_{\mathrm{x}}\left(\mathrm{O}\right.$ and $\left.\mathrm{O}_{3}\right)$ at $t=1 \mathrm{~s}$ and $1 \mathrm{~h}$ in Fig. 4, and these temporal variations at $40 \mathrm{~km}$ in Fig. 5. The excited state $\mathrm{O}\left({ }^{1} \mathrm{D}\right)$ diminishes completely within $1 \mathrm{~s}$ through dissociation of $\mathrm{H}_{2} \mathrm{O}$ and ionmolecular reactions, although its production has a similar magnitude as $\mathrm{O}\left({ }^{3} \mathrm{P}\right)$. For $\mathrm{O}$ and $\mathrm{O}_{3}$, the response is relatively 

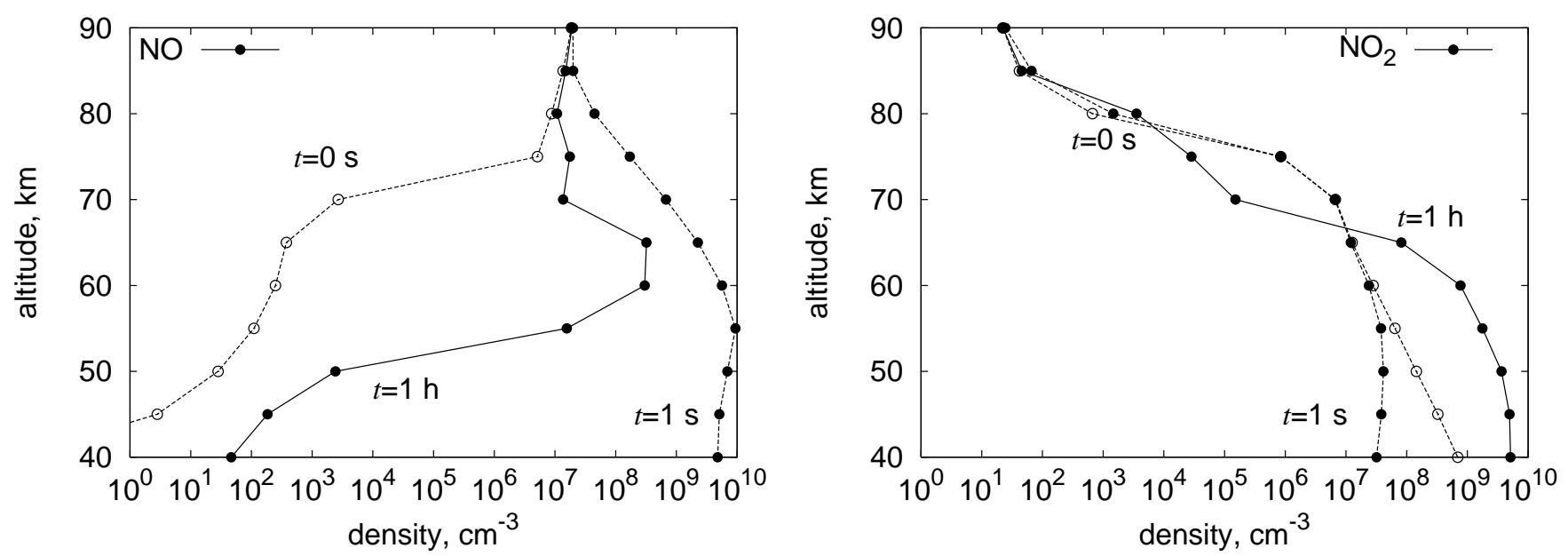

Fig. 2. The density variations for $\mathrm{NO}_{\mathrm{x}}\left(\mathrm{NO}\right.$ and $\left.\mathrm{NO}_{2}\right)$ species at the periods of $t=1 \mathrm{~s}$ (dashed lines with closed circles) and $1 \mathrm{~h}$ (solid lines) after the initiation of a sprite streamer $(t=0)$ at the nighttime condition, dashed lines with open circles showing these initial values.

simple, i.e. linear to the sprite impact $(\sim \mathrm{N})$, except for some contributions to other species, such as the loss of $\mathrm{NO}_{2}$ by $\mathrm{O}$ and destruction of $\mathrm{HO}_{2}$ and $\mathrm{OH}$ (see R11 and R12). It is mentioned that the $\mathrm{O}$ atom increases first and then $\mathrm{O}_{3}$ increases as the following series of key reactions;

$$
\begin{aligned}
& \mathrm{O}_{2}+\mathrm{e} \rightarrow \mathrm{O}\left({ }^{1} \mathrm{D}\right)+\mathrm{O}+\mathrm{e} \\
& \mathrm{O}+\mathrm{O}_{2}+\mathrm{M} \rightarrow \mathrm{O}_{3}+\mathrm{M} .
\end{aligned}
$$

These processes (conversion of $\mathrm{O} \rightarrow \mathrm{O}_{3}$ ) are considered to occur below $70 \mathrm{~km}$. Figure 5 clearly shows that $\mathrm{O}_{3}$ is the final sink of $\mathrm{O}_{\mathrm{x}}$ to sprite impact, while $\mathrm{O}$ decreases in a scale of $<10^{3} \mathrm{~s}$. Consequently, the increasing rate of $\mathrm{O}_{3}$ by a single sprite streamer becomes maximum at $40 \mathrm{~km}$, up to a factor of 4 ; its density amounts to $\approx 2 \times 10^{12} \mathrm{~cm}^{-3}$. Because the maximum production of $\mathrm{O}$ and $\mathrm{O}\left({ }^{1} \mathrm{D}\right)$ is $P_{\mathrm{diss}} t_{\mathrm{s}} \approx 5 \times 10^{11} \mathrm{~cm}^{-3}$ through the process (R6), other processes, such as ionization $\left(\mathrm{O}_{2}^{+}, \mathrm{O}^{+}\right)$and excitation $\left(\mathrm{O}_{2}(\mathrm{a})\right)$ of $\mathrm{O}_{2}$, and process ( $\left.\mathrm{R} 2\right)$, also have a large contribution to the ozone production within a scale of $1-100 \mathrm{~s}$.

Next, we show density distributions of $\mathrm{HO}_{\mathrm{x}}\left(\mathrm{H}, \mathrm{OH}, \mathrm{HO}_{2}\right.$, and $\mathrm{H}_{2} \mathrm{O}_{2}$ ) at $t=1 \mathrm{~s}$ and $1 \mathrm{~h}$ in Fig. 6 , and these time variations at $40 \mathrm{~km}$ and $60 \mathrm{~km}$ in Fig. 7. The response of $\mathrm{HO}_{\mathrm{x}}$ is found to be more complicated and unexpected than those of the other species $\mathrm{NO}_{\mathrm{x}}$ and $\mathrm{O}_{\mathrm{x}}$. We investigate first the main trigger reaction of $\mathrm{HO}_{\mathrm{x}}$ density changes within $t=1$ $\mathrm{s}$ at $40 \mathrm{~km}$, where atomic hydrogen $\mathrm{H}$ and hydroxyl radical $\mathrm{OH}$ increase strongly with a nearly linear dependence on the sprite impact. Contrary to our expectation that the sprite-produced $\mathrm{O}\left({ }^{1} \mathrm{D}\right)$ contributes mainly through the reactions $\mathrm{H}_{2}+\mathrm{O}\left({ }^{1} \mathrm{D}\right) \rightarrow \mathrm{H}+\mathrm{OH}$ and $\mathrm{H}_{2} \mathrm{O}+\mathrm{O}\left({ }^{1} \mathrm{D}\right) \rightarrow 2 \mathrm{OH}$ as similar to lower-thermospheric chemistry, more of a contribution is made by electrons produced through the following reactions until the time of $1 \mathrm{~ms}$ :

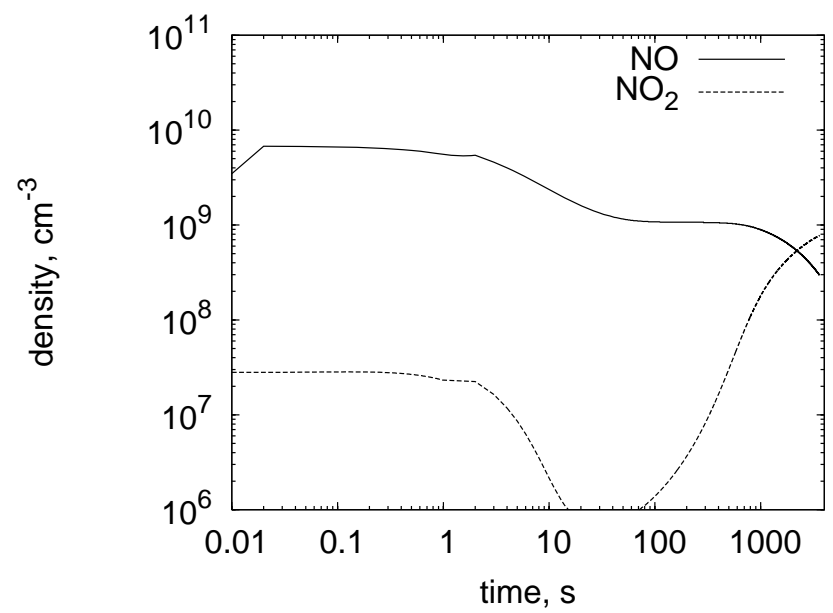

Fig. 3. Temporal density variations for $\mathrm{NO}_{\mathrm{x}}$ species at $60 \mathrm{~km}$ altitude in the same condition as Fig. 2; solid and dashed lines show those of $\mathrm{NO}$ and $\mathrm{NO}_{2}$, respectively, after initiation of streamer at $t=0$.

$$
\begin{aligned}
& \mathrm{H}_{3} \mathrm{O}^{+} \mathrm{OH}+\mathrm{e} \rightarrow \mathrm{H}+\mathrm{OH}+\mathrm{H}_{2} \mathrm{O} \\
& \mathrm{HNO}_{3}+\mathrm{e} \rightarrow \mathrm{OH}+\mathrm{NO}_{2}^{-} .
\end{aligned}
$$

Thus, both $\mathrm{H}$ and $\mathrm{OH}$ increase extremely. However, these reactions concede the position of a main trigger to the following ones by the time when the ions and electrons relax to the initial densities $(t \approx 1 \mathrm{~s})$,

$$
\begin{aligned}
& \mathrm{H}+\mathrm{O}_{3} \rightarrow \mathrm{OH}+\mathrm{O}_{2} \\
& \mathrm{HO}_{2}+\mathrm{O} \rightarrow \mathrm{OH}+\mathrm{O}_{2} \\
& \mathrm{OH}+\mathrm{O} \rightarrow \mathrm{H}+\mathrm{O}_{2},
\end{aligned}
$$




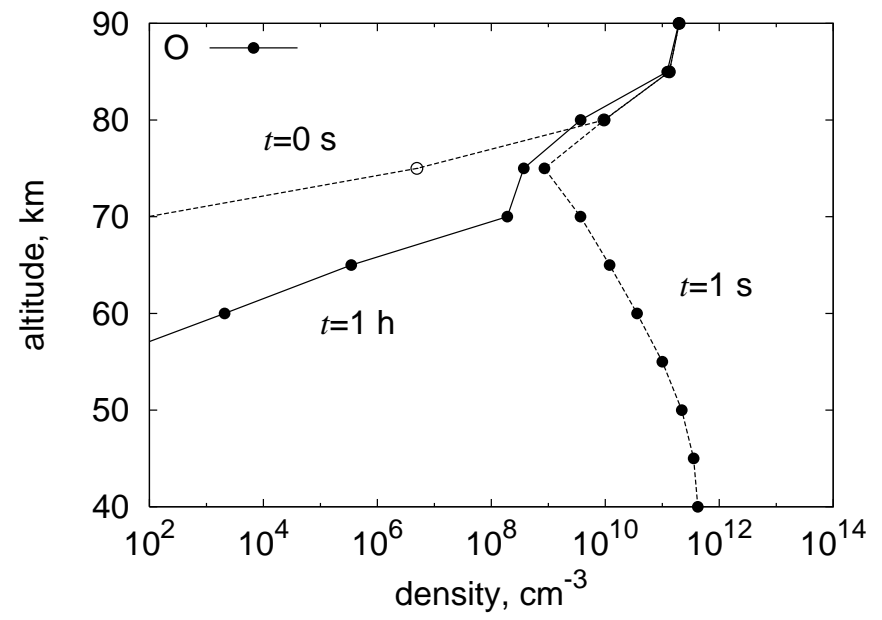

Fig. 4. Same as Fig. 2, but shown are for $\mathrm{O}_{\mathrm{x}}\left(\mathrm{O}\left({ }^{3} \mathrm{P}\right)\right.$ and $\left.\mathrm{O}_{3}\right)$ species.

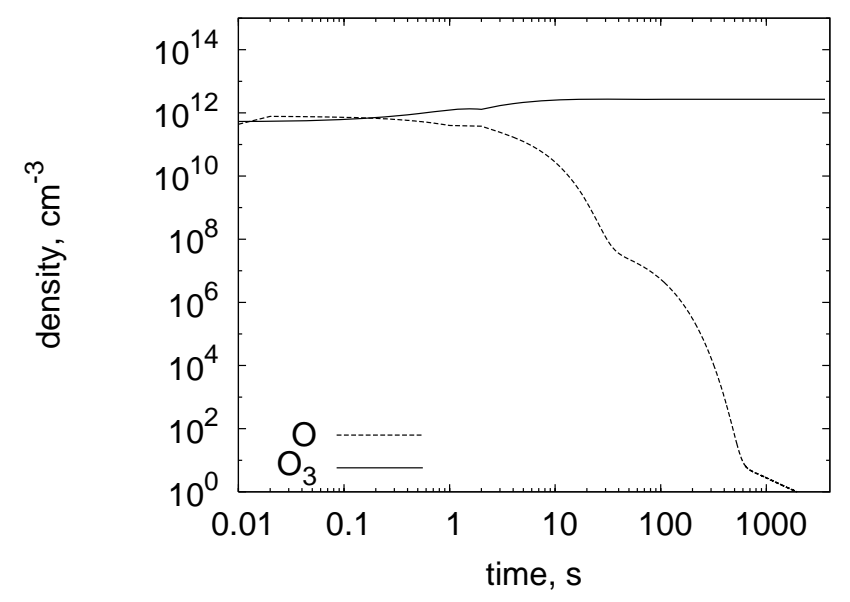

Fig. 5. Temporal density variations for $\mathrm{O}_{\mathrm{x}}$ species at $40 \mathrm{~km}$ in the same condition as Fig. 4; solid and dashed lines show those of $\mathrm{O}_{3}$ and $\mathrm{O}$, respectively.

showing a successive multiplication. In addition, Fig. 6 shows that increases in $\mathrm{HO}_{2}$ by 1-4 orders of magnitude in the range of $40-55 \mathrm{~km}$ and in $\mathrm{H}_{2} \mathrm{O}_{2}$ by several factors in the range of $55-65 \mathrm{~km}$ follow. We would mention here briefly the difference in the responses between these two molecules at $t \approx 1-100 \mathrm{~s}$. We confirmed that $\mathrm{HO}_{2}$ is produced with not only oxidation of $\mathrm{H}$ and $\mathrm{OH}$ but with the destruction of $\mathrm{H}_{2} \mathrm{O}_{2}$ by $\mathrm{O}, \mathrm{OH}$, and $\mathrm{H}$. A large increase in $\mathrm{HO}_{2}$ at $40 \mathrm{~km}$ is due to considerable increases in $\mathrm{H}$ and $\mathrm{OH}$, whereas the rate becomes smaller in the upper altitude, substituted for the production of $\mathrm{H}_{2} \mathrm{O}_{2}$. A relatively small but constant increase in $\mathrm{H}_{2} \mathrm{O}_{2}$ around $40-70 \mathrm{~km}$ is due mainly to nonlinear reactions of $\mathrm{HO}_{2}+\mathrm{HO}_{2} \rightarrow \mathrm{H}_{2} \mathrm{O}_{2}+\mathrm{O}_{2}$ and $\mathrm{OH}+\mathrm{OH}+\mathrm{M} \rightarrow \mathrm{H}_{2} \mathrm{O}_{2}+\mathrm{M}$. Figure 7 also shows that in a time scale of $\approx 100 \mathrm{~s}$ almost all $\mathrm{H}$, with small intrinsic lifetime, converts to $\mathrm{OH}$ and $\mathrm{HO}_{2}$, followed by a large increase in $\mathrm{H}_{2} \mathrm{O}_{2}$ through destructions

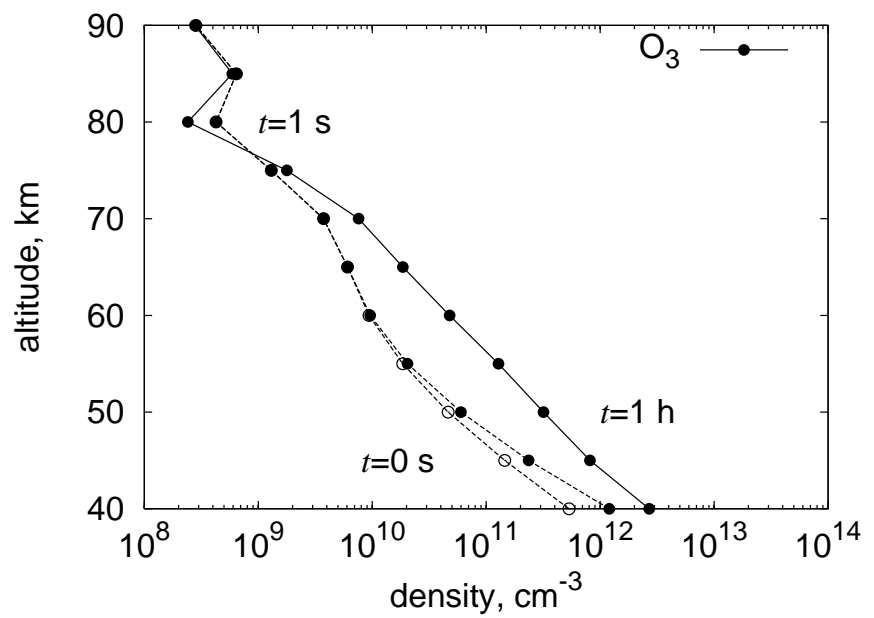

of these two molecules, with $\mathrm{OH}$ mainly having a fast relaxation time at $40 \mathrm{~km}$ and an enhancement at $60 \mathrm{~km}$. At $t=1$ hour the increasing rate of $\mathrm{H}_{2} \mathrm{O}_{2}$ at $40 \mathrm{~km}$ is finally at $\approx 1$ order of magnitude; its density amounts to $\approx 7 \times 10^{7} \mathrm{~cm}^{-3}$. Around $60 \mathrm{~km}$, the increasing rate shows a similar tendency, in spite of a slow reduction rate of $\mathrm{OH}$, due to a slow relaxation of $\mathrm{H}$. It is mentioned that $\mathrm{HO}_{2}$ and $\mathrm{H}_{2} \mathrm{O}_{2}$ are the final sinks to the sprite impact at $40 \mathrm{~km}$ with increasing rates by 3 orders and 1 order of magnitude, respectively, while those of $\mathrm{OH}$ and $\mathrm{H}_{2} \mathrm{O}_{2}$ at $60 \mathrm{~km}$ with increases by 2 orders and 1 order of magnitude, respectively, where $\mathrm{HO}_{2}$ relaxes within $t \approx 10^{3} \mathrm{~s}$.

We tried to interpret roughly the longtime behaviors over $100 \mathrm{~s}$ in $\mathrm{HO}_{2}$ and $\mathrm{H}_{2} \mathrm{O}_{2}$ with a steady-state analysis. We find that the source reactions of $\mathrm{HO}_{2}$ are mainly those of $\mathrm{OH}$ with $\mathrm{O}_{3}$ and $\mathrm{H}_{2} \mathrm{O}_{2}$, while its loss reaction is concerned with $\mathrm{NO}_{\mathrm{x}}\left(\mathrm{NO}, \mathrm{NO}_{2}\right)$ such as three-body one $\mathrm{HO}_{2}+\mathrm{NO}_{2}+\mathrm{M} \rightarrow \mathrm{HO}_{2} \mathrm{NO}_{2}+\mathrm{M}$. Its density can be approximately written as $\left[\mathrm{HO}_{2}\right] \propto\left(\Delta\left[\mathrm{O}_{3}\right]+\Delta\left[\mathrm{H}_{2} \mathrm{O}_{2}\right]\right) / \Delta\left[\mathrm{NO}_{\mathrm{x}}\right]$, assuming variable terms are dominant. The $\mathrm{HO}_{2}$ density would not change largely around $60 \mathrm{~km}$ because of the rapid reduction of $\mathrm{NO}$, with no increase in $\mathrm{NO}_{2}$, and moderate increases in $\mathrm{O}_{3}$ and $\mathrm{H}_{2} \mathrm{O}_{2}$ (see Figs. 2 and 4). Over the altitude, it decreases a little by the effective increase in NO. On the other hand, it increases in the range of $40-50 \mathrm{~km}$ in accord with increases of $\mathrm{O}_{3}$ and $\mathrm{H}_{2} \mathrm{O}_{2}$, more effective than that of $\mathrm{NO}_{2}$, where $\mathrm{NO}$ already relaxes.

Next, the source reactions of $\mathrm{H}_{2} \mathrm{O}_{2}$ are mainly reactions of $\mathrm{OH} \times 2$ or $\mathrm{HO}_{2} \times 2$ shown above, while its loss reaction is concerned with $\mathrm{OH}$; the loss processes by $\mathrm{O}$ and $\mathrm{H}$ atoms do not contribute so much due to their fast relaxation. Its density increases in the wide range through nonlinear loss of enhanced $\mathrm{OH}$, thus, $\left[\mathrm{H}_{2} \mathrm{O}_{2}\right] \propto \Delta[\mathrm{OH}]$; it remains at $1 \mathrm{~h}$ by constant increases in $\mathrm{HO}_{2}$ at $60 \mathrm{~km}$ and $\mathrm{OH}$ at $40 \mathrm{~km}$, i.e. $\left[\mathrm{H}_{2} \mathrm{O}_{2}\right] \propto\left(\Delta\left[\mathrm{HO}_{2}\right]_{60 \mathrm{~km}}+\Delta[\mathrm{OH}]_{40 \mathrm{~km}}\right) / \Delta[\mathrm{OH}] \approx$ const. 

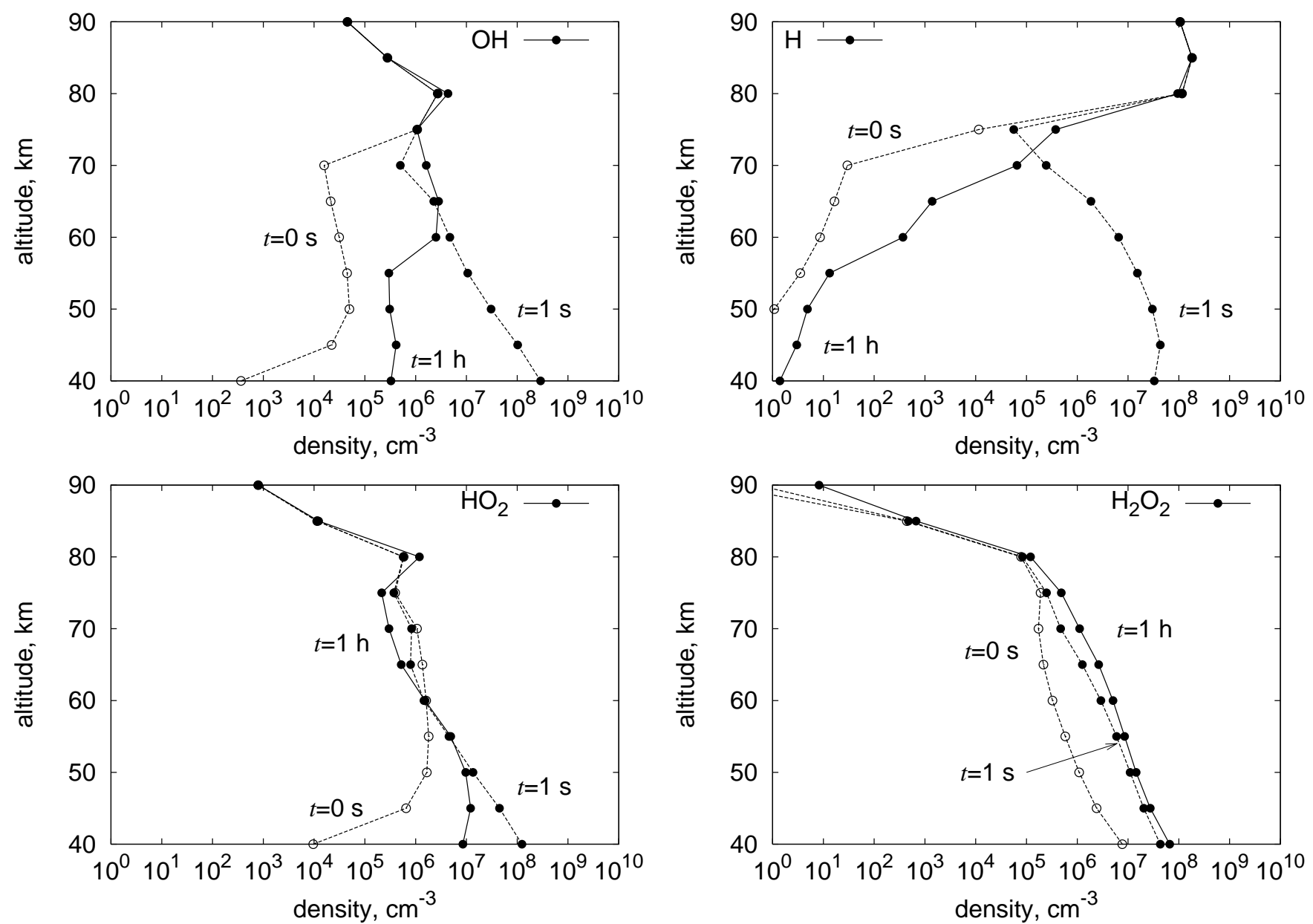

Fig. 6. Same as Fig. 2, but shown are for $\mathrm{HO}_{\mathrm{x}}\left(\mathrm{OH}, \mathrm{H}, \mathrm{HO}_{2}\right.$, and $\left.\mathrm{H}_{2} \mathrm{O}_{2}\right)$ species.

We discuss possible uncertain factors for our calculation shown above, even if it is only an order-estimation: (i) accuracy in molecular chemical reaction coefficient, (ii) uncertainty in the streamer-tip electric field magnitude, and (iii) contribution of the other part of streamer (i.e. body or beadstructure). We first compare the reaction rate coefficients we used with newer ones. In the above discussion, the key reactions for $\mathrm{NO}_{\mathrm{x}}$ chemistry are Reaction (R2) as a trigger (NO being secondary product), Reactions (R3)-(R5) (sink to $\mathrm{NO}_{2}$ ), and $\mathrm{N}+\mathrm{NO} \rightarrow \mathrm{N}_{2}+\mathrm{O}$; the keys for $\mathrm{O}_{\mathrm{x}}$ are Eq. (7), and for $\mathrm{HO}_{\mathrm{x}}, \mathrm{H}_{2}\left(\mathrm{H}_{2} \mathrm{O}\right)+\mathrm{O}\left({ }^{1} \mathrm{D}\right) \rightarrow \mathrm{H}+\mathrm{OH}(2 \mathrm{OH})$ and Reactions (R10)-(R12) as triggers, $\mathrm{OH}+\mathrm{OH}+\mathrm{M} \rightarrow \mathrm{H}_{2} \mathrm{O}_{2}+\mathrm{M}$ and $\mathrm{HO}_{2}+\mathrm{HO}_{2} \rightarrow \mathrm{H}_{2} \mathrm{O}_{2}+\mathrm{O}_{2}$, etc. We referred to the compiled data of DeMore et al. (1994) for these reaction coefficients. Comparing their updated data of Sander et al. (2006), almost all of the above $\mathrm{NO}_{\mathrm{x}}$ and $\mathrm{O}_{\mathrm{x}}$ reactions are unchanged except for Reaction (R3) having a difference of $<1 \%$ at $250 \mathrm{~K}$, while for $\mathrm{HO}_{\mathrm{x}}$ the difference is less than $30 \%$ at $250 \mathrm{~K}$. From these facts we consider that the uncertainty in rate coefficients is below our estimation.
Next, we perform a response study as to how much the results vary with the streamer electric field. When the magnitude is set to be in the range of 400-800 Td, the NO density at $t=1$ hour varies in the scale of 1 order around the value in Fig. 2. However, our conclusion remains essentially unchanged because the difference is found to be almost linear to the amount of first product, i.e. $k$. Here it is difficult to mention the details about the effect on other species with their increasing scales of 1-2 orders of magnitude, which is the same order as the above variation.

We focus in our model only on the impact of the streamer tip with a strong electric field. It is suggested that the tail part is actually formed after the tip passes away, in which a slightamplitude electric field exists, despite not causing a strong electron acceleration and optical emission (Liu and Pasko, 2004); $E / N \geq 60 \mathrm{Td}$. From optical measurement of sprites, the bead-like structures with strong emissions are found to be formed in the region where a cluster of streamers exists (Gerken and Inan, 2002; Moudry et al., 2003). Both lifetimes are in the range of $\approx 1-10 \mathrm{~ms}$. We estimate in this paper that the former effect is negligibly small and the latter 

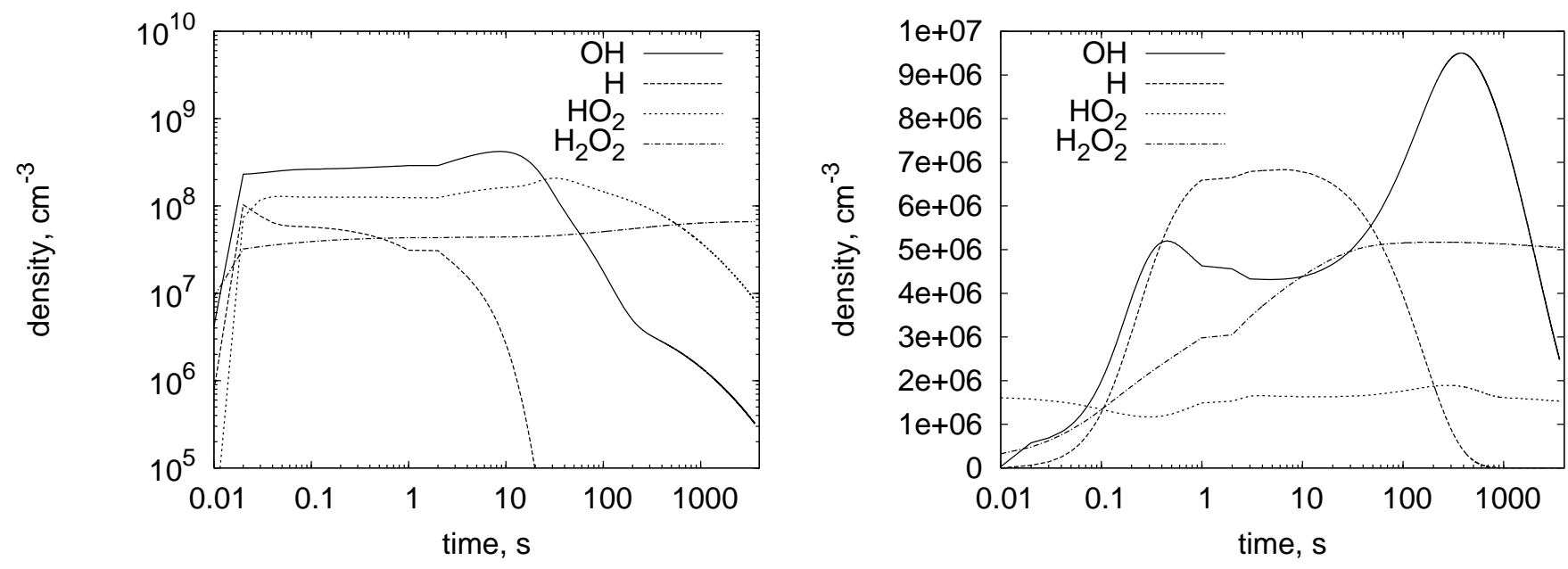

Fig. 7. Temporal density variations for $\mathrm{HO}_{\mathrm{x}}$ species at $40 \mathrm{~km}$ (left panel) and $60 \mathrm{~km}$ (right panel) in the same condition as Fig. 6; solid, dashed, dotted, and dashed-dotted lines show those of $\mathrm{OH}, \mathrm{H}, \mathrm{HO}_{2}$, and $\mathrm{H}_{2} \mathrm{O}_{2}$, respectively.

one cannot be evaluated due to a lack of its mechanism to date; this should be done in our future studies. Our speculation to this problem is made as follows. We consider that the predominantly produced particles in the streamer tail are metastable states, such as $\mathrm{N}_{2}(v=1)$ and $\mathrm{N}_{2}(\mathrm{~A})$ rather than $\mathrm{N}$ and $\mathrm{O}$ atoms of great importance in our calculations. As a mechanism, the multiple excitation is needed to gain dissociation energy and to cause the density variation of $\mathrm{NO}_{\mathrm{x}}$ and $\mathrm{HO}_{\mathrm{x}}$ triggered by these particles; the highly excited secondary and ternary products dissociate $\mathrm{N}_{2}$ and $\mathrm{H}_{2}$. However, these processes are expected not to be so dominant in our transient discharge, with a small lifetime and a small particle production, different from a stable glow discharge.

\section{Discussion}

On the basis of the above results we try to estimate roughly the sprite impact on local chemistry at nighttime. Here we examine whether the mean density variation for a certain species survives or not when the impact is mixed in a local area as in a similar approach by Hiraki et al. (2004). We estimate below the impact of $\mathrm{NO}$, of which density variation by a streamer is up to 6 orders of magnitude at $60 \mathrm{~km}$ is the largest in all target species. Here we assume the horizontal scale of sprites, with a cluster of streamers being $100 \mathrm{~km}^{2}$ at their maximum. The local area is defined to be $10^{6} \mathrm{~km}^{2}$ as the typical resolution of satellites, e.g. ENVISAT-Sciamachy (limb emission sounder), in which the increasing rate of NO is reduced as $1 / 10^{4}$ through mixing without any loss. However, the calculated variation can survive evidently with 2 orders of magnitude in spite of the wide-range mixing. Within our estimation being only for one event, the impact will be larger in the area such as Africa, where many events of lightning and sprites are possible within several hours. It would still be significant even though this kind of estimation depends certainly on the initial condition; we discuss this point in the final paragraph. We emphasize that the density increase of NO is detectable if a certainly resolved and qualified observation is performed. Note that this discussion is limited to the nighttime impact because of the abundance of daytime $\mathrm{NO}$ and $\mathrm{NO}_{2}$. It is one of the future studies of this field as to whether integration of nighttime variation in $\mathrm{NO}_{\mathrm{x}}$ by many sprite events affects these diurnal variations.

We offer some comments as to the future observational studies through a comparison with our results. Our estimation is done on purpose to determine the upper limit with an uncertainty of a few orders of magnitude due to the streamer electric field and scale parameters, so that it requires verification with observation. Since the sprite impact on chemical species varies widely with altitude, sub-millimeter wave limb emission sounders, such as ENVISAT-Sciamachy and ODIN-SMR, are adequate to detect it; these probes measure the densities of $\mathrm{NO}, \mathrm{NO}_{2}$, and $\mathrm{O}_{3}$ above $40 \mathrm{~km}$ altitude with moderate accuracy. The measurements at nighttime or predawn are desirable. It is better if the horizontal resolution is less than $1000 \mathrm{~km}$; a detectable limit becomes higher and traces in various species such as $\mathrm{O}_{3}$ and $\mathrm{OH}$ can be achieved. As one of these trials, the results of Arnone et al. (2008), using ENVISAT-MIPAS as a $10 \%$ density increase of $\mathrm{NO}_{2}$, are comparable with ours as 1 order of increase (Figs. 2 and 3). We can make a similar estimation as above using the fieldof-view $\left(1.5 \times 10^{4} \mathrm{~km}^{2}\right)$ of the sensor they showed. As the reduction factor is $10^{-2}$ assumed for the scale of streamers $100 \mathrm{~km}^{2}$, our $\mathrm{NO}_{2}$ density enhancement is consistent with their values, if tens of sprites can be produced in a couple 
of hours. This could be sufficiently expected for the case of an active thunderstorm. More reliable consistency will be obtained by a future cooperative assessment between theory and observation.

Another possible method to demonstrate the density increase of $\mathrm{NO}_{\mathrm{x}}$ is the spectroscopic observations of direct sprite emissions, as previously done by Morrill et al. (2002). Pasko (2007) suggested a possibility of NO- $\gamma$ band emission in sprites on the basis of analogy with laboratory steady-state corona discharges. For its mechanism they showed that the interaction of $\mathrm{O}$ and $\mathrm{N}\left({ }^{2} \mathrm{D}\right)$ with $\mathrm{N}_{2}(\mathrm{~A})$, all of which are the first products of electron impact processes, leads to the formation of $\mathrm{NO}\left(\mathrm{X}^{2} \Pi_{r}\right)$; it interacts again with $\mathrm{N}_{2}(\mathrm{~A})$ to form the $\mathrm{NO}\left(\mathrm{A}^{2} \Sigma^{+}\right)$state, which is the source of $\gamma$ band emission. In the streamer-type transient discharge of our interest, such a dominant production of the $\mathrm{NO}\left(\mathrm{A}^{2} \Sigma^{+}\right)$state and $\gamma$ emission as the steady-state case are not expected. This is due to the short duration of streamer transverse and the small amounts of the above secondary and ternary products, as mentioned in the end of Sect. 3. However, it can certainly contribute to the sprite emission in the wavelength range of $150-280 \mathrm{~nm}$ of the ISUAL spectrophotometer on board FORMOSAT-2, as they have pointed out. We emphasize that this photometric observation aims at the estimation of enhancement of the NO ground state by sprites. We also encourage the ground-based spectroscopic observations with fine spatial and wavelength resolutions to identify its $\gamma$ emission.

Finally, we compare our calculation results with other studies. To date, the similar calculations are done by Enell et al. $(2005,2008)$. They showed the increasing rate of the NO density after initiation of a sprite streamer in the nighttime condition (in summer and low solar activity). The increasing rates are $2-3$ orders of magnitude at $40-50 \mathrm{~km}$ at its maximum, and are a few percents above the altitude range. They also show in the longtime behavior that the NO density relaxes to the initial value within $1 \mathrm{~h}$. The response at this altitude range is very similar to our results, however, above that the altitude is quite different. We elaborate by mentioning the response around $60 \mathrm{~km}$, which is important in the viewpoint of atmospheric chemistry, where the rate in our case is instantaneously 6 orders of magnitude. The difference in the rate is mostly due to the difference in the evaluation of the sprite first products as input parameters. It should be pointed out that we give altitude dependence of the production rate on the basis of scaling law of streamer dynamics and include all possible particles produced through e- $\mathrm{N}_{2}, \mathrm{O}_{2}$ inelastic collisions. Enell et al. (2008) showed the dissociation rates of $\mathrm{O}_{2}$ in the altitude range of $50-80 \mathrm{~km}$ as $10^{7}-10^{10} \mathrm{~cm}^{-3} \mathrm{~s}^{-1}$. In comparison, their values are considerably smaller than our input values as $k_{\text {diss }} n_{\mathrm{e}} N \approx 10^{11}-10^{13} \mathrm{~cm}^{-3} \mathrm{~s}^{-1}$ in the similar range (see Fig. 1). It would be due to the time averaging effect on the measurement of the streamer emission intensity, causing an underestimation of the production rates. We mention further the dependence on the initial values of the chemical model adopted. At $60 \mathrm{~km}$ the initial value of NO density is in our case $\approx 10^{2} \mathrm{~cm}^{-3}$, while in theirs it is $\approx 10^{6} \mathrm{~cm}^{-3}$. As we mentioned at the beginning of Sect. 3, the difference seems to be due to the boundary conditioning of NO. It is, however, asserted that the increasing rate of NO density by 2-3 orders of magnitude would be obtained if we calculate with more appropriate values, because its lifetime in their case is considered to be much larger than that in our case. It would be still detectable with satellite sounder observations if 100 sprites occur within a couple of hours, similar to the above discussion.

\section{Summary}

We estimate density variations of $\mathrm{NO}_{\mathrm{x}}, \mathrm{O}_{\mathrm{x}}$, and $\mathrm{HO}_{\mathrm{x}}$ families on the basis of ion chemistry driven by non-thermal electron kinetics in sprite streamer. We evaluate chemically radical particle production by the electrons with an exact kinetic method. Results at nighttime condition show that the densities of $\mathrm{NO}, \mathrm{O}_{3}, \mathrm{OH}$, and $\mathrm{H}$ considerably increase through reactions triggered by sprite first products as $\mathrm{O}, \mathrm{N}$, and electrons in the time scale of $1-10 \mathrm{~s}$. It is demonstrated that the impacts on several species, such as $\mathrm{NO}, \mathrm{NO}_{2}, \mathrm{O}_{3}$, and $\mathrm{H}_{2} \mathrm{O}_{2}$, last over one hour by a certain order of increase at the range of $40-70 \mathrm{~km}$. It is considered that these longtime behaviors are related to source-sink balances of $\mathrm{NO}-\mathrm{NO}_{2}$ and of $\mathrm{HO}_{2}-\mathrm{H}_{2} \mathrm{O}_{2}$, newly constructed by sprite products. We expect that the sprite impacts on these minor species will be detectable with highly qualified satellite observations, such as ENVISAT-MIPAS and Sciamachy which we discussed here. For detailed research we should overcome the difficulties in the chemical model, uncertainty over 1 order of magnitude due to initial conditions and particle production rates. We point out to future theoretical works to make an estimation of a series of sprites, with a short time-delay, consisting of a cluster of streamers, including multi-dimensional overlapping and mixing effects.

Acknowledgements. We thank Yukikazu Itikawa for providing his updated compilation of electron- $\mathrm{N}_{2}$ collision cross sections. We thank Naomoto Iwagami for providing his chemical model of neutral constituents. Y. H. thanks Atsushi Ichimura and Yukihiro Takahashi for discussions on electron atomic-molecular processes and on the viewpoint of sprite observation, respectively.

Edited by: J. Curtius

\section{References}

Arnone, E., Kero, A., Dinelli, B. M., Enell, C.-F., Arnold, N. F., Papandrea, E., Rodger, C. J., Carlotti, M., Ridolfi, M., and Turunen, E.: Seeking sprite-induced signatures in remotely sensed middle atmosphere $\mathrm{NO}_{2}$, Geophys. Res. Lett., 35, L05807, doi:10.1029/2007GL031791, 2008.

Borisov, N. D., Kozlov, S. I., and Smirnova, N. V.: Changes in the chemical composition of the middle atmosphere during multi- 
ple microwave pulse discharge in the air, translated from Kosm. Issled., 31, 63-74, 1993.

Brasseur, G.: Atmospheric chemistry and global change, Oxford Univ. Press, New York, 1999.

Cosby, P. C.: Electron-impact dissociation of nitrogen, J. Chem. Phys., 98, 9544-9553, 1993a.

Cosby, P. C.: Electron-impact dissociation of oxygen, J. Chem. Phys., 98, 9560-9569, 1993b.

DeMore, W. B., Golden, D. M., Hampson, R. F., Howard, C. J., Kurylo, M. J., Molina, M. J., Ravishankara, A. R., and Sander, S. P.: Chemical Kinetics and Photochemical Data for Use in Stratospheric Modeling, Evaluation, Number 11, JPL Publication 9426, Jet Propulsion Laboratory, California Institute of Technology, Pasadena, CA, 1994.

Enell, C-F., Verronen, P. T., Seppälä, A., Turunen, E., and Ulich, T.: Possibility of NO production by transient luminous events studied in a coupled ion-neutral chemical model, 9th IAMAS Assembly, Beijing, 2005.

Enell, C.-F., Arnone, E., Adachi, T., Chanrion, O., Verronen, P. T., Seppälä, A., Neubert, T., Ulich, T., Turunen, E., Takahashi, Y., and Hsu, R.-R.: Parameterisation of the chemical effect of sprites in the middle atmosphere, Ann. Geophys., 26, 13-27, 2008, http://www.ann-geophys.net/26/13/2008/.

Gerken, E. A., and Inan, U., S.: A survey of streamer and diffuse glow dynamics observed in sprites using telescopic imagery, J. Geophys. Res., 107(A11), 1344, doi:10.1029/2002JA009248, 2002.

Hiraki, Y., Tong, L., Fukunishi, H., Nanbu, K., Kasai, Y., and Ichimura, A.: Generation of metastable oxygen atom $\mathrm{O}\left({ }^{1} \mathrm{D}\right)$ in sprite halos, Geophys. Res. Lett., 31, L14105, doi:10.1029/2004GL020048, 2004.

Hiraki, Y. and Fukunishi, H.: Theoretical criterion of charge moment change by lightning for initiation of sprites, J. Geophys. Res. 111, A11305, doi:10.1029/2006JA011729, 2006.

Itikawa, Y.: Electron collisions with $\mathrm{N}_{2}, \mathrm{O}_{2}$, and $\mathrm{O}$ : what we do and do not know, Adv. Atomic Mol. Opt. Phys., 33, 253-274, 1994.

Itikawa, Y: Cross sections for electron collisions with nitrogen molecules, J. Phys. Chem. Ref. Data, 35, 31-53, doi:10.1063/1.1937426, 2006.

Iwagami, N., Inomata, S., and Ogawa, T.: Doppler detection of hydrO $\mathrm{x}_{\mathrm{x}} \mathrm{yl}$ column abundance in the middle atmosphere: 2 . measurements for three years and comparison with a $1 \mathrm{D}$ model, J. Atmos. Chem., 29, 195-216, 1998.

Kulikovsky, A. A.: Production of chemically active species in the air by a single positive streamer in a nonuniform field, IEEE Trans. Plasma Sci., 25, 439-446, 1997.

Liu, N. and Pasko, V. P.: Effects of photoionization on propagation and branching of positive and negative streamers in sprites, J. Geophys. Res., 109, A04301, 2004.
Mätzing, H.: Chemical kinetics and flue gas cleaning by irradiation with electrons, Adv. Chem. Phys., 80, 315-402, 1991.

McHarg, M. G., Haaland, R. K., Moudry, D. R., and StenbaekNielsen, H. C.: Altitude-time development of sprites, J. Geophys. Res., 107(A11), 1364, doi:10.1029/2001JA000283, 2002.

Morrill, J. S., Bucsela, E. J., Siefring, C., Heavner, M. J., Berg, S. L., Moudry, D. R., Slinker, S., Fernsler, R., Wescott, E. M., Sentman, D. D., and Osborne, D.: Electron energy and electric field estimates in sprites derived from ionized and neutral $\mathrm{N}_{2}$ emissions, Geophys. Res. Let., 29(10), 1462, 10.1029/2001GL014018, 2002.

Moudry, D. R., Stenbaek-Nielsen, H. C., Sentman, D. D., and Wescott, E. M.: Imaging of elves, halos and sprite initiation at $1 \mathrm{~ms}$ time resolution, J. Atmos. Solar-Terr. Phys., 65, 509-518, 2003.

Neubert, T., Allin, T. H., Blanc, E., Farges, T., Haldoupis, C., Mika, A., Soula, S., Knutsson, L., van der Velde, O., Marshall, R. A., Inan, U., Sátori, G., Bór, J., Hughes, A., Collier, A., Laursen, S., and Lundgaard Rasmussen, I.: Co-ordinated observations of transient luminous events during the EuroSprite2003 campaign, J. Atmos. Solar-Terr. Phys., 67, 807-820, 2005.

Pasko, V. P.: Red sprite discharges in the atmosphere at high altitude: the molecular physics and the similarity with laboratory discharges, Plasma Sources Sci. Technol., 16, S13-S29, doi:10.1088/0963-0252/16/1/S02, 2007.

Pasko, V. P., Inan, U. S., and Bell, T. F.: Spatial structure of sprites, Geophys. Res. Lett., 25, 2123-2126, 1998.

Raizer, Y. P.: Gas Discharge Physics, 1st ed., Springer-Verlag, New York, 1991.

Sander, S. P., Finlayson-Pitts, B. J., Friedl, R. R., Golden, D. M., Huie, R. E., Keller-Rudek, H., Kolb, C. E., Kurylo, M. J., Molina, M. J., Moortgat, G. K., Orkin, V. L., Ravishankara, A. R., and Wine, P. H.: Chemical Kinetics and Photochemical Data for Use in Atmospheric Studies, Evaluation Number 15, JPL Publication 06-2, Jet Propulsion Laboratory, Pasadena, 2006.

São Sabbas, F. T., Sentman, D. D., Wescott, E. M., Pinto, O., Mendes, O., Taylor, M. J.: Statistical analysis of space-time relationships between sprites and lightning, J. Atmos. Solar-Terr. Phys., 65(5), 525-535, 2003.

Sentman, D. D. and São Sabbas, F. T.: Energy deposition of sprites in the middle-upper atmosphere, 3rd Brazilian Workshop on Atmospheric Electricity, Brazil, 2002.

Stenbaek-Nielsen, H. C., Moudry, D. R., Wescott, E. M., Sentman, D. D., and São Sabbas, F. T.: Sprites and possible mesospheric effects, Geophys. Res. Lett., 27, 3829-3832, 2000.

Tochikubo, F., and Arai, H.: Numerical simulation of streamer propagation and radical reactions in positive corona discharge in $\mathrm{N}_{2} / \mathrm{NO}$ and $\mathrm{N}_{2} / \mathrm{O}_{2} / \mathrm{NO}$, Jpn. J. Appl. Phys., 41, 844-852, 2002. 